\title{
Fire and rescue service community safety initiatives: measuring impact
}

Author(s):

Thomas Simpson (Transfer Partnership (KTP) Associate, based at Emergency Services

Research Unit (ESRU), Division of Psychology, Nottingham Trent University, Nottingham, UK)

Dan Wheatley (Senior Lecturer in Economics, based at Nottingham Business School

(Member of the Applied Economics and Policy Research Group), Nottingham Trent

University, Nottingham, UK)

Vivienne Brunsden (Principal Lecturer in Psychology, based at Head of Emergency Services

Research Unit (ESRU), Division of Psychology, Nottingham Trent University, Nottingham, UK)

Rowena Hill (Senior Lecturer in Psychology, based at Emergency Services Research Unit (ESRU), Division of Psychology, Nottingham Trent University, Nottingham, UK)

Citation:

Thomas Simpson, Dan Wheatley, Vivienne Brunsden, Rowena Hill, (2014) "Fire and rescue service community safety initiatives: measuring impact", Safer Communities, Vol. 13 Iss: 2 , pp.88 - 100

DOI

http://dx.doi.org/10.1108/SC-01-2013-0001

Downloads:

The fulltext of this document has been downloaded 75 times since 2014

Abstract:

Purpose

- The purpose of this paper is to discuss methods of capturing the impact of fire and rescue service (FRS) community safety work which directly aims to reduce the occurrence of specific incidents.

\section{Design/methodology/approach}

- The impact assessment method described focuses on addressing one of the major problems with regards to attributing outcomes to FRS community safety work; the influence of external factors. This paper looked to assess the incident trends within a case study UK FRS within the context of the following external data sets: first, incident trends within other UK FRSs; second, demographic trends; and third, incident data from other public services.

\section{Findings}

- There were instances, either across the whole region served by the case study FRS, or within specific districts, where evidence suggested a strong likelihood of the community safety work of the case study FRS contributing towards an observed reduction in incidents. These findings were established through filtering the impact of widespread external factors, which could impact upon incident figures. 


\section{Research limitations/implications}

- The utility of this impact assessment relies upon FRS consistently recording the specific aims and focus of individual community safety activity, so that any positive outcomes can be attributed to a particular group of community safety initiatives.

\section{Originality/value}

- This paper discusses how an evaluation process, to determine the likelihood of community safety impacting upon incident numbers, can be practically applied to a FRS.

Keywords:

$\underline{\text { Evaluation, Community safety initiatives, Fire and rescue service, Impact assessment }}$

Publisher:

Emerald Group Publishing Limited

Acknowledgments:

This research formed part of a wider research project between Nottinghamshire Fire and Rescue Service (NFRS) and Nottingham Trent University (NTU), the purpose of which is to develop evaluation methods which can be used to measure the impact of NFRS' community safety initiatives. The partnership received financial support from the Knowledge Transfer Partnerships programme (KTP). KTP aims to help businesses to improve their competitiveness and productivity through the better use of knowledge, technology and skills that reside within the UK Knowledge Base. KTP is funded by the Technology Strategy Board along with the other government funding organisations.

\section{Article}

\section{Introduction}

Section:_i7

The role of the UK fire and rescue service (FRS) has changed in recent years, moving from one of response only to a dual role of prevention and response. A significant proportion of these changes have been incorporated within the Local Government Modernisation Agenda (LGMA) (Matheson et al., 2011). The Fire and Rescue Services Act (2004) stated that a UK FRS must make provisions for the purpose of promoting safety, meaning that their primary aim is to reduce risk within communities in addition to responding to fire incidents and other emergencies. Consequently FRSs in the UK focus efforts upon delivering community safety initiatives and events within their communities; providing information, publicity and encouragement in order to reduce risk. These developments of the roles and requirements of a FRS have not only been observed within the UK. A recent study examined a series of case studies concerning the community safety strategies being put in place to reduce the risk of wildfire within Australia, Canada and the USA. A wide acceptance was reported for the need to engage with members of the public, providing them with safety information, in order to reduce risk (McGee, 2011).

One of the major changes which have been experienced by the UK FRSs has been the move towards a culture in which they have a responsibility to identify their own risks locally (Ewen, 2004). The UK Fire and Rescue Service National Framework (Department for Communities and Local Government (DCLG), 2012) emphasises the need for a FRSs risk reduction and prevention work to be responsive to the prominent safety issues of their local communities, identified within their 
Integrated Risk Management Plans (IRMPs). This view has been made clear within the UK policy documents (Cabinet Office, 2012), with the suggestion that the key to effective governance involves bringing FRSs as close as possible to the communities they serve. This reflects a key intention of the governing political parties to take power away from central Government and disperse it to a more local level (Localism Act, 2011).

The policy changes from central government, in light of public sector spending cuts, have necessitated many UK FRSs to conduct in depth reconsiderations of their foci, organisational structures and spending (Murphy et al., 2012), in order to implement the significant changes required to comply with new policies. Concerns have been raised in some areas as to whether these changes could have a detrimental impact on public safety. The Fire Brigade's Union (FBU, 2012), for example, has suggested that unprecedented increases in incidents, which could occur as a result of adverse weather conditions, will "threaten to expose the impact of frontline cuts". Similar concerns could be attributed to community safety work, which is also experiencing a reduction in resources. Consequently, given that public safety is paramount to all parties involved, any suggested changes to the community safety agenda and its allied initiatives should be supported by an accurate and well considered evidence base. An increased understanding of the most effective forms of community safety activity can be achieved through developing effective methods of evaluation. The implementation of appropriate evaluation methods can highlight those initiatives which are likely to be producing positive outcomes, as well as those initiatives which are not achieving intended outcomes and consequently require amendment. Such information is particularly useful considering the costs involved in both resource and financial terms, due to the potential for efficiency savings (Baum, 2001).

Again these challenges are not specific to the UK only. A series of workshops conducted by The US Fire Administration and National Institute of Standards Technology (NIST) in October 1999 highlighted that there was a need for the fire service to undertake a greater level of evidence-based assessment in order to support policies and decisions (Moeller, 2007); an issue which is directly applicable to community safety work. There is a strong need for an improved understanding of how to measure the effectiveness of community safety work which focuses on reducing the risks of specific types of incidents (McCaffrey, 2004).

Developing methods that enable evaluation of the impact of community safety provides a FRS with the potential not only to increase efficiency savings but also to demonstrate their own positive impact within the community, and consequently protect vital community safety work from budget cuts (Morton, 2006). In recent years FRS have made use of evaluation methods in order to assess the impact of community safety initiatives and subsequently gain information to inform future practice. Ta et al. (2006) carried out a literature review of evaluated US fire prevention activities which had taken place between 1998 and 2004, reporting upon findings which would have the potential to increase the efficiency of future risk prevention initiatives. Evaluation has indicated that more intensive targeted canvassing methods (e.g. community safety staff visiting individual properties in contrast to canvassing in public areas through distributing flyers), are more likely to lead to individuals obtaining smoke alarms.

Other evaluations have led to findings which can guide future methods of educational safety information delivered to school children. Terry et al. (2000) reported evidence that communitybased approaches appeared to be effective in increasing some safety practices, such as bicycle helmet use and car seat use amongst children, but were less likely to impact upon child pedestrian safety and adolescent vehicle safety. However, Terry et al. (2000) reported that there was no research to support the assumption that changes in knowledge lead to changes in behaviour. This problem has been further reiterated in subsequent research, with little evidence to suggest educational programmes impact upon self-reported safety behaviours (Kendrick et al., 2007). This illustrates a significant problem in terms of evaluating the long-term impacts of educational initiatives, as it is much less reliable to attribute impact to longer term outcomes due to greater 
exposure to the influence of external factors. Ultimately there are factors in the external environment which might impact upon an initiative's chances of success (O'Connor, 1995), meaning that often it is very difficult to determine what would have happened in the initiative's absence (Baum, 2001).

Within this paper the focus will be placed upon methods which can be used in order to evaluate the impact of initiatives which directly aim to reduce incidents in the short term. For instance Lowton et al. (2010) investigated a joint approach between the fire and rescue and health services in order to work together to deliver both Home Safety Checks (HSCs) and falls assessments to elderly residents in two London boroughs. This illustrates an initiative responding to a current risk issue with an aim to directly influence short-term incident figures. However, for such initiatives the problem of determining the impact of external factors still remains. As they are directly impacting upon incident figures, though, a more tangible impact assessment can be carried out, as the measurement of incident trends is a valid outcome measurement.

Taking into account the fact that FRS record information regarding every incident they attend, it makes practical sense to analyse this secondary data in order to evaluate the impact of initiatives, particularly considering that the more traditional methods of experimentation would not be ethically robust or safe in the context of evaluating community safety.

One of the ways in which this data can be utilised for evaluation purposes is through benchmarking incident trends against other FRSs in order to define an expected performance level; a method which has been highlighted as being of great value within the context of evaluation within fire and rescue services (Wentling, 2000; Granito, 2009; Arch and Thurston, 2013). In addition, the use of data from other public agencies can also provide further insight to assist with determining impact. Research carried out by Moeller (2007) emphasised the need for an evidence-based culture in a FRS to involve the assistance of external agencies.

It is important to emphasise that, in most circumstances, any impact upon incident figures can only be attributed to a collection of initiatives and events. A report into the evaluation options for UK FRSs stated that fire incident data should only be used as an outcome measure to assess impact across a relatively wide area over a significant period of time. For instance very often it would not be reliable to assess the impact of a single initiative focusing upon reducing accidental dwelling fires by focusing upon incident numbers within the neighbourhood during the preceding weeks and months, as such incidents are generally infrequent. Instead it would be more appropriate to assess the collective impact of all initiatives which have focused upon reducing accidental dwelling fires within a particular region over a longer period of time, as this is likely to provide a larger data set, thus allowing meaningful benchmarking information which can contribute towards an impact assessment.

An impact assessment within this context needs to acknowledge that cause and effect can never fully be established, due to the large number of external factors which are likely to be impacting upon whether or not the aim of community safety work is achieved (Baum, 2001). External factors such as civil unrest could have a negative impact upon incident figures, while external factors such as safer electrical appliances could have a positive impact upon incident figures. The influence of external factors will always be responsible for a certain degree of ambiguity; for the reason that it is not possible to control for all of them. However, a greater understanding of the likelihood of a FRS's impact upon incident figures can be determined through assessing incident trends in conjunction with relevant external data sets.

\section{Method}

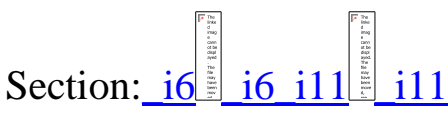

FRSs across the UK have implemented a wide range of community safety initiatives which aim to achieve safer homes, roads and neighbourhoods within the communities they serve. To an extent the 
impact of specific community safety initiatives can be analysed through identifying a specific type of incident they aim to reduce and assessing the changes in the occurrence of such incidents. This impact assessment illustrates how evaluation methods can be applied to a FRS, through using incident data taken from an area served by a UK FRS.

\section{Design}

The impact assessment focused upon a case study of a single UK FRS, in which secondary data analysis was carried out upon FRS incident data, within the context of incident data from other public services and data documenting changes in demographics. However, the intention was to identify data collection and analysis methods which could be replicated across the FRS in general.

The case study FRS serves an entire county of England, looking after more than one million people who live, work, visit or travel through the county every day. There are almost 30 fire stations across the county, which include those which are fully whole time, partly whole time and partly retained and fully retained, with this allocation of resources driven by the need of the local area. A team of over 100 staff support this work, focusing upon providing information to assist the service in its different remits of work; delivery, protection, prevention and resilience.

As the design of the impact assessment was to focus upon methods which could be used to measure the impact of community safety initiatives aiming to reduce specific types of incidents, the two outcome measures selected were:

1. 1. the occurrence of deliberate secondary fires, and;

2. 2. the occurrence of accidental dwelling fire casualties.

The rationale behind this was that the FRS delivered community safety initiatives focusing upon directly reducing these types of incidents.

Community safety initiatives of the case study FRS

The FRS delivers initiatives which focus upon working with young people who have been involved in, or are at risk of being involved in, deliberate fire setting behaviour. Direct referrals are made to the FRS from the police, social workers, schools or parents. Due to the nature of deliberate fire setting incidents the FRS is unable to record information regarding the perpetrators. The FRS also works with partner organisations, in order to address any specific risk issues which are contributing towards, either directly or indirectly, the occurrence of deliberate secondary fires.

The FRS, further, delivers HSCs to selected households within the county, which involves carrying out a safety check within the home to ensure it is free from fire hazards and that the appropriate safety precautions are in place and functioning. Consequently this is an initiative which can be directly aligned with aiming to reduce the incidences of accidental dwelling fires and the risk of injury from accidental dwelling fires. In a broader sense, many more of the FRS initiatives place focus upon safety measures which should be adopted in the home in order to reduce the risk of fire and the risk of injury from a fire; from educating school children to attending community events in which the FRS provide the general public with safety information. However, HSCs are the specific initiative which can be most directly linked to aiming to reduce the occurrence of such incidents.

Data collection

Data from 1 April 2006 to 31 March 2011 was collected to illustrate methods which could be used to determine the impact of community safety work in the county which had focused upon reducing: deliberate secondary fires and accidental dwelling fire casualties. This was considered to be a suitable time period to assess the collective impact of initiatives which had focused upon contributing towards the same outcome. The number of deliberate secondary fires and accidental dwelling fire casualties which the FRS attended to during the 2006/2007 year (1 April 2006 to 31 
March 2007) were compared to the number which they had attended to during the 2010/2011 year (1 April 2010 to 31 March 2011), and the percentage rate of change was calculated.

The rate of change in the number of deliberate secondary fires was placed into context through assessing, across the same time period: first, the rate of change in the number of deliberate secondary fire incidents across wider regions in the UK (between 1 April 2006 and 31 March 2011); second, the rate of change in population (2006-2010) and; third, the rate of change in the number of offences recorded by the police (between 1 April 2006 and 31 March 2011). The number of offences recorded by the police was taken from the Office of National Statistics (ONS, 2013).

The offences recorded by the police were the collective total of the following types of incidents: violence against the person, all wounding or endangering life, harassment including incidents leading to penalty notices for disorder, common assault, robbery, theft from the person, criminal damage including arson, burglary in a dwelling, burglary other than a dwelling, theft of a motor vehicle and theft from a motor vehicle. It is important to highlight that although the National Crime Recording Standards, which guide the way in which police data are recorded and categorised, have been similar for a number of years, some groups will have had additions or deductions as a result of criminal law changing. For instance the quarterly crime statistics for the period to June 2008 in England and Wales indicated a 22 per cent increase in the number of "most serious violence" offences recorded by the police, thus creating negative media attention. However, the Home Office claimed that the majority of this was due to alterations in the counting rules surrounding GBH with intent (Berman, 2008). This is not a huge issue with regards to the analysis described within this paper, as only the broad group of offences recorded by the police are being assessed, however, the contextual background still needs to be acknowledged.

It is important to note that it is only appropriate to use crime data when focusing upon evaluating community safety initiatives specifically focused upon reducing deliberate fires, which makes its application quite specific. This is important to note due to the fact that a significant proportion of FRS community safety initiatives focus upon reducing accidental incidents.

The rate of change in the number of accidental dwelling fire casualties was placed into context through assessing, across the same time period: first, the rate of change in the number of accidental dwelling fire casualties across wider regions in the UK (1 April 2006 - 31 March 2011) and; second, the rate of change in the population of the age group considered as being at a higher risk of being involved in such incidents (2006-2010).

The rationale behind studying these external data sets was, where possible, to control for the impact of widespread external factors, which could have also impacted upon incident figures. This includes external factors such as: first, those which could be impacting upon incident numbers across an entire region or country (for instance changes in legislation); second, increases or decreases in the population which could be reflected in incident figures or; third, the prevention efforts from the police which could contribute towards FRS incident figures. Taking into consideration these different information sources conclusions were established to consider the likelihood of the FRS community safety work contributing to a proportion of any changes in incident numbers.

\section{Results}

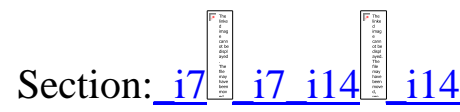

The incident data highlights that there has been a substantial reduction in both the number of deliberate secondary fires and accidental dwelling fire casualties which the case study FRS 
attended. However, assessments can only be made regarding the likelihood of community safety work impacting upon these decreases through obtaining relevant contextual information.

\section{Deliberate secondary fires}

Analysing the data, Table I highlights that substantial reductions have been observed in the number of deliberate secondary fires within the case study FRS (46.79 per cent reduction), as well as at a regional level, amongst the FRS benchmarking group, and at a national level (the FRS Benchmarking Group refers to a group of FRS in the UK which the case study FRS is benchmarked against due to the fact they have similar risk profiles; in term of size and population).

Tables I and II also illustrate that at local, regional and national levels, as well as within all the districts within the case study FRS, there has been an increase in population. Table II indicates that substantially larger decrease rates in the number of deliberate secondary fires (by a margin of greater than 5 per cent) have been observed within districts $\mathrm{D}, \mathrm{G}$ and $\mathrm{H}$ of the case study FRS. It also indicates that substantially smaller decrease rates in the number of deliberate secondary fires have been observed within districts A, B and F. Table II, further, indicates that in a number of the case study FRS districts the rate of the decrease in deliberate secondary fires has been in excess of that observed for offences recorded by the police (districts A, D, G and H). It also indicates that in a number of the case study FRS districts the rate of the decrease in the deliberate secondary fires has been substantially smaller than that observed for offences recorded by the police (districts $\mathrm{B}$ and $\mathrm{F}$ ).

Taking into consideration: first, the rate of decrease in the number of deliberate secondary fires within districts $\mathrm{D}, \mathrm{G}$ and $\mathrm{H}$ in comparison to those observed locally, regionally and nationally; second, the rate of decrease in offences recorded by the police within districts $\mathrm{D}, \mathrm{G}$ and $\mathrm{H}$, and; third, the over-riding context of population increase, there is evidence to suggest that there are factors, specific to these districts, which have contributed towards the reductions in deliberate secondary fires observed. Equally, however, the data also highlights that within some districts (districts A, B and F) there is evidence to suggest that there are factors, specific to the districts, which are contributing towards the district experiencing a far smaller rate of reduction in deliberate secondary fires.

\section{Accidental dwelling fire casualties}

In respect to accidental dwelling fire casualties, Table III highlights that the numbers of accidental dwelling fire casualties which the case study FRS attended have decreased at a rate far greater than that observed regionally and nationally. This finding is of significance, particularly considering that it has occurred during a time period in which the case study FRS have become more targeted towards the higher risk individuals within the delivery of their HSCs (see Table

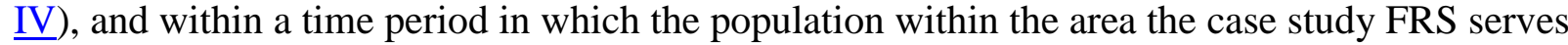
has increased (see Table III). More specifically, however, the most consistent increases in population at the greatest rates are occurring within the elderly age groups, as highlighted within Table V. This is of significance considering that the weighted percentages in Table V indicate that the elderly groups within the area which the case study FRS serves are at a disproportionate risk of experiencing an injury as a result of an accidental dwelling fire.

In this instance analysis was only carried out for accidental dwelling fire casualties across the area served by the case study FRS, as in contrast to deliberate secondary fire incidents, the numbers of accidental dwelling fire casualties within the individual districts were generally very small, meaning that assessing rates of percentage change would not have been appropriate.

Taking into consideration: first, the rate of decrease in the number of accidental dwelling fire casualties which the case study FRS have attended to in comparison to the decrease rates at regional and national levels; second, the population increase within the area which the case study 
FRS serves, particularly amongst high-risk groups and; third, the more targeted approach towards HSCs by the case study FRS, there is evidence to suggest that the community safety initiatives of the case study FRS contributed towards the reductions in accidental dwelling fire casualties observed within the county.

\section{Discussion}

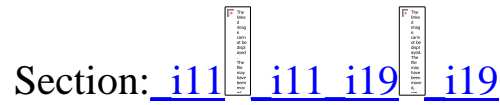

Interpretation of findings

The larger rate of decrease in the number of deliberate secondary fires within districts $D, G$ and $\mathrm{H}$ in comparison to: the case study FRS as a whole; the local region; the FRS benchmarking group and; England, indicates that any widespread external factors which impact upon deliberate secondary fire incidents cannot be fully attributed to the decreases observed within districts $D, G$ and $\mathrm{H}$. A proportion of any decrease in incidents could be attributed to population change if the population has decreased, but the data illustrates that this is not the case. Across the region which the case study FRS serves there has been an increase in population. Finally, within districts D, G and $\mathrm{H}$ the rate of decrease in deliberate secondary fires is greater than the rate of decrease in the number of offences recorded by the police. This indicates that within these areas any external factors which have been contributing towards reductions in criminal activity, such as initiatives administered by the police, cannot be fully attributed to the reduction observed for deliberate secondary fires. These findings together are indicative of factors, specific to these districts, contributing towards the reductions in deliberate secondary fire incidents.

The smaller rate of decrease in the number of deliberate secondary fires within districts A, B and F in comparison to: the case study FRS as a whole; the local region; the FRS benchmarking group; England and; the rate of change in the number of offences recorded by the police (districts $\mathrm{B}$ and $\mathrm{F}$ ), indicates that any widespread external factors which are impacting upon reducing deliberate secondary fire incidents are not as influential within these districts, suggesting the presence of external factors specific to these districts.

The larger rate of decrease in the number of accidental dwelling fire casualties within the area served by the case study FRS in comparison to: the local region; the FRS benchmarking group and; England, indicates that any widespread external factors which impact upon accidental dwelling fire casualties cannot be fully attributed to the decreases observed within the area served by the case study FRS. This suggests that the community safety initiatives of the case study FRS have contributed towards the decrease in the number of accidental dwelling fire casualties within the area. A proportion of any decrease in incidents could be attributed to population change if the population has decreased, but the data illustrates not only that the population is increasing but that the greatest rates of increase are occurring within the elderly age groups; the age group which data indicates are disproportionately at risk of injury from an accidental dwelling fire. Notwithstanding this external factor, the reduction in incidents observed provides further support for the likelihood of the case study FRS' initiatives having a positive impact in reducing the risk of injury from an accidental dwelling fire.

There is a clear distinction between the interpretations of the incident trends surrounding the deliberate secondary fire incidents in comparison to the accidental dwelling fire casualty incidents. When analysing the deliberate secondary fire incident rates one can only suggest that there is evidence of an impact and cannot attribute it to the community safety work of the case study FRS, due to the fact that data are not available concerning the focus and delivery of community safety initiatives which were focused upon reducing deliberate secondary fires. For example, if a particular area has experienced a reduction in incidents which is far in excess of the regional and national average, yet has not been targeted with any community safety initiatives 
during the time period in question, the reduction cannot be attributed to community safety work and is likely to have occurred as a result of localised external factors. In contrast, there is more validity in suggesting that the community safety initiatives of the case study FRS contributed towards the reduction in accidental dwelling fire casualties, due to the fact that there is data highlighting an increasing number of high-risk HSCs being carried out within the time period.

Measuring and recording short-term impacts

These methods of impact assessment are useful for capturing the impact of community safety work which aims to address the current risk related issues; whether they are targeting a group or an area which incident data indicates is high risk. However, in order to capture positive impact it is imperative that community safety work is consistently recorded. Data indicating a strong likelihood of positive impact within a particular area during a particular time period, in respect of a reduction in the occurrence of a particular type of incident, is limited in use for a FRS without accurate and detailed information concerning the community safety work taking place at that time.

Arch and Thurston (2013) assessed the impact of HSCs, administered by a UK FRS, in reducing domestic fires and related injuries. Information regarding the delivery of these initiatives was crucial in enabling an impact assessment to be completed. The data collected indicated that a significantly greater decrease had occurred within the area served by the FRS in question, in comparison to other UK FRS, during a period in which the FRS in question had commenced a uniquely large scale targeted HSC initiative. The analysis of the incident trends, in the context of the data concerning the proportion of HSCs which had been administered, provided evidence to suggest that it was likely that the HSCs had contributed towards reducing domestic fires and related injuries. Ultimately consistent and accurate data concerning the administration of community safety initiatives is imperative in order for FRSs to be in a position to increase their understanding of the forms of community safety initiatives which make a significant contribution.

Consequently when attributing community safety work as being responsible for a proportion of a reduction in incidents, stakeholders need to be clear regarding the rationale for individual community safety initiatives, including where they took place, what they aimed to achieve, and whether they were successful (including how this was measured). This will increase validity in assessing the impact of a collection of initiatives, in respect to decreases in incidents. For example, the impact assessment method illustrated within this paper could generate the conclusion that within a particular area there is a strong likelihood of a positive impact, in terms of the FRS's community safety contribution towards reducing accidental dwelling fires. Community safety data during the specified time period could indicate that a large number of community engagement events had taken place; the individual aims of which were to engage with lone parent families, as recent historical data identified them to be the group at the highest risk of experiencing an accidental dwelling fire. Short-term evaluation methods for the individual events could highlight that they were all successful in engaging with the target group, thus adding legitimacy to the suggestion that the collective impact of these events can be attributed to a proportion of any observed reduction in accidental dwelling fires.

Conducting measurable short-term evaluation of individual community safety initiatives and events is important to facilitate a longer term evaluation of collective community safety work. The evaluation applied to FRS community safety initiatives/events can be classified as being either short term (attendance of target group/increased awareness of safety amongst them), intermediate (increased sense of responsibility leading to more safety cautious behaviour) or long term (reduction in the number of incidents). In practice the evaluation of individual community safety initiatives and events can usually only go as far as short-term evaluation (although there are exceptions). Attributing widespread longer term impacts to individual initiatives, or events, is 
not reliable. For example, previous research which has looked to investigate the impact of FRS community safety work upon longer term impacts, which are most frequently incident rates, have focused upon assessing the impact of a collection of widespread initiatives which have had a common focus, such as the targeting of particular areas during particular time periods with home safety assessments (Arch and Thurston, 2013) or the installation and promotion of smoke alarms (DiGuiseppi et al., 2002; DiGuiseppi and Higgins, 2000; Mallonee, 2000).

However, if stakeholders have information regarding the short-term outcomes of individual initiatives and events they will be in a more informed position to determine whether a collection of initiatives are likely to have contributed to any positive impacts identified, through the method of using external data sets to place incident trends into context. For example, a widespread initiative across a particular area could be focused upon promoting smoke alarm ownership, with the long-term aim to reduce domestic fires. The shorter term evaluation of the individual interventions which form this initiative, such as a demonstration at a particular community centre, could focus upon whether individuals have obtained smoke alarms since receiving the safety information. Such information has proved particularly significant in past research as Roberts et al. (2004) carried out a follow up assessment of a random selection of households which had received free smoke alarms as a result of a government recommendation to local authorities. It was found that there was a low level of functioning smoke alarms due to the distress which had been caused through false alarms. Consequently in this instance there would be no sense in looking to analyse longer term impacts, due to the knowledge that the short-term aim had not been achieved. Therefore in order to implement an effective evaluation process a FRS need to initially focus upon evaluating individual community safety initiatives through assigning them with measurable aims, which are attributable to the initiative.

\section{Limitations}

It is important to acknowledge the limitations of the data sets which have been used to illustrate this impact assessment. The incident figures from the case study FRS were benchmarked against regional and national trends in order to control for the impact of widespread external factors. This methodology could have been improved if the case study FRS was compared, not only to other FRS which served a similar area in terms of size and population, but FRS serving areas of a similar demographic profile and similar levels of deprivation. This would reduce the likelihood of one taking into account external factors which are of no relevance to the area served by the case study FRS. In addition to this, any significant differences could be investigated through comparing the community safety initiatives of the FRSs, as well as the governance of the community safety initiatives.

The deliberate secondary fire incidents were benchmarked against overall crime in order to control for the impact of policing activity. However, it is true to say that this is limited due to the fact that overall crime is very broad, meaning that it would be more useful to benchmark deliberate secondary fires against a more specific crime, which is more closely related to deliberate secondary fires. This would require further research, in order to determine whether deliberate secondary fires follow the trends of another type, or group, of crimes recorded by the police.

It is important to take into consideration the very difficult nature of recording information surrounding incidents that the FRS attends. For example, it can be extremely difficult to determine whether a secondary fire is accidental or deliberate. Therefore if FRS do not have a consistent and shared approach to address this, there are likely to be issues regarding the reliability of the data, particularly when comparing incidents trends between different services.

The data used within this impact assessment to illustrate the evaluation methods, compares incident figures across a five-year period. In reality it would be of far greater utility for a FRS to compare figures across a smaller time period, particularly considering that the purpose of using 
these evaluation methods is to determine whether positive impacts can be attributed to specific community safety initiatives.

The evaluation method utilises secondary data analysis, which has the advantage of being an efficient method which has the potential to be implemented within any UK FRS, as it is utilising existing data sets. Without the use of such methods potentially useful information is lost through the lack of any robust data analysis being conducted on the vast amounts of data that are routinely collected by the Fire \& Rescue Service. However, there are also a number of limitations arising from the use of such existing data sets; notably that the data have not been collected specifically for a particular research design which might limit its fit to the particular question under consideration. Further, in relation to questions of cause and effect, pre-post designs necessarily have greater validity in terms of establishing the direct pattern of causation. Despite such limitations secondary data analysis is a legitimate approach to take within research and has the potential to reveal important information that might otherwise be missed, as well as laying a foundation for further investigations. In this specific case, whilst assessing the number of accidental dwelling fire casualties is a valid method to use in order to evaluate the impact of HSCs it should also be acknowledged that focusing solely upon this data set in isolation is somewhat restrictive. The collection of further data, for example, through carrying out pre and post knowledge tests on safety practices with those who have received HSCs, could provide an even greater understanding as to why a particular trend is occurring and which aspects of the intervention are having the greatest impact.

Estimating financial impacts

The main limitation of the impact assessment methods described is the immeasurable impact of external factors which can never be fully controlled for, meaning that the impact assessment method can only be used to draw conclusions which state the likelihood or probability of community safety initiatives impacting upon incident figures. Further, as the process is still relatively vague, in that the conclusions which are drawn can only be used to indicate that there is a strong probability of community safety work contributing towards a proportion of a reduction in incidents, placing a financial value upon this is not particularly useful. The average cost of a particular type of incident could be calculated, leading to an overall figure highlighting the financial savings from incident reductions. However, all that could be concluded from this would be that there is a strong probability of community safety work contributing towards a proportion of the financial saving. In addition, the calculation of the cost of an incident is a complicated process, particularly if the wider costs are included regarding the broader consequences for society. However, estimates into this have been calculated, specifically within a report produced by the DCLG (2012) into the economic cost of fires in 2008.

Providing an estimate for the financial cost of a fatality or an injury is more problematic, not least in respect to the moral questions this raises. Implicit judgements are made by policy makers everyday regarding the value of a casualty or an injury. Within the context of the fire service it is the driving force behind the notion that a large proportion of community safety initiatives are focused upon reducing domestic fires, as these are the incidents in which an injury or death is most likely to occur. There are costs associated with injuries which are more straightforward to assign a financial value; such as the costs of treatment to the health service or the loss of output for the economy through time lost in working hours. It is difficult, though, to assign a cost to the emotional and physical suffering associated with an injury (Boardman et al., 2011). For these reasons, assigning a financial value to the impact of community safety work is not appropriate. A non-monetary impact assessment is the most appropriate method. 


\section{Conclusion}

Section:_i14_i14_i25_i25

Conducting an impact assessment using the methods highlighted is only useful for a FRS if it has a consistent process of data recording and short-term evaluation to support it. Consequently measurable aims need to be applied to individual community safety initiatives so that stakeholders have a sound understanding of the overall focus and success of community safety initiatives and events within particular areas during particular time periods. This will ensure they are in a more informed position to attribute community safety work as being responsible for a degree of any positive impact upon incident figures. For example, the case study FRS' HSCs had been successful in targeting a greater proportion of high-risk households, adding further weight to the suggestion that they contributed towards recorded incident reductions. Therefore the effectiveness of the process is reliant upon a bottom up system; whereby if accurate data are not recorded concerning individual community safety initiatives and events, stakeholders cannot attribute impact and make strategic decisions regarding the focus of community safety work with any validity or reliability.

This system can lead to an effective evaluation process for a FRS in multiple respects. First, the application of accurate and measurable aims to community safety initiatives ensures that valid evaluation takes place. This means that the success of initiatives and events are assessed in a way which is fair; hence the fire service carrying out community engagement at a single event is not evaluated through measuring subsequent incident rates, but through assessing whether they have engaged with the target group. Second, the generation of this data will allow stakeholders to determine whether the focus of community safety work aligns with the overall risk concerns within that particular area. This is particularly important considering the changing needs of the community, as the predominant risk concerns of five years ago may have changed given the present economic and policy environment. In order for a FRS to be in a position to identify specific time periods within specific areas where there is a likelihood of community safety work contributing towards incident reductions they must be required to: place any incident trends into context through studying external data sets and; collect data concerning the focus of individual events and initiatives so that collective events and initiatives can be attributed to longer term outcomes.

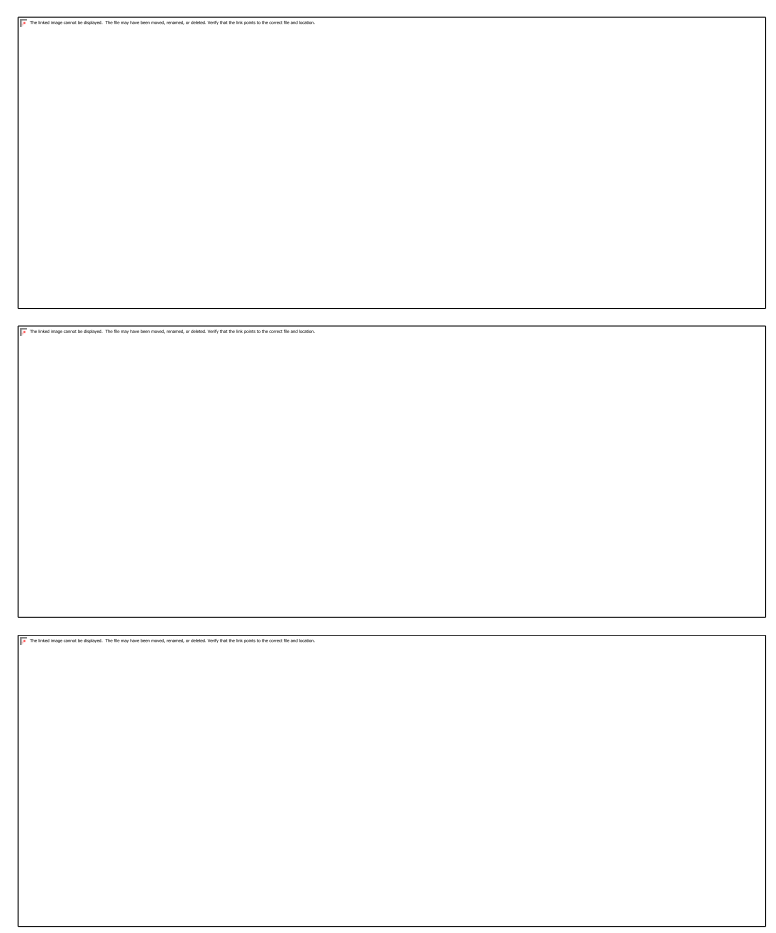




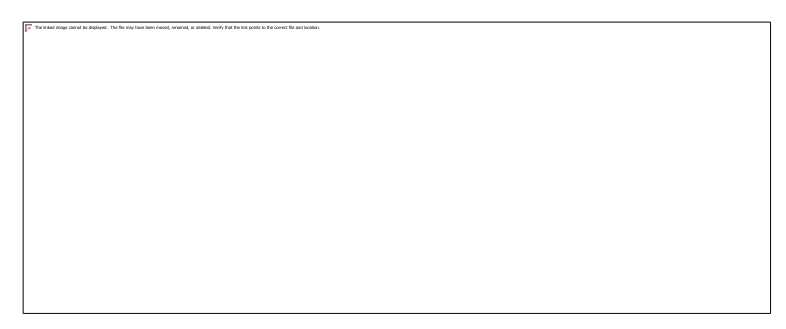

\section{References}

1.

Arch, B.N. and Thurston, M.N. (2013), “An assessment of the impact of home safety assessments on fires and fire-related injuries: a case study of Cheshire fire and rescue service", Journal of Public Health, Vol. 35 No. 2, pp. 200-205. [CrossRef], [ISI] [Infotrieve]

2.

Baum, H.S. (2001), "How should we evaluate community initiatives?", Journal of the American Planning Association, Vol. 67 No. 2, pp. 147-66. [CrossRef], [ISI] [Infotrieve] 3.

Berman, G. (2008), "Changes in crime recording practices. Social and general statistics. Library: House of Commons", available at:

http://data.parliament.uk/briefingpapers/PublisherService.svc/briefingpapers/SN02607.pdf (accessed 10 October 2011).

4.

Boardman, A. , Greenberg, D. , Vinning, A. and Weimer, D. (2011), Cost-Benefit Analysis: Concepts and Practice, 4th ed., Prentice Hall, New Jersey.

5 .

Cabinet Office (2012), Open Public Services, White Paper, HMSO, London.

6.

Department for Communities and Local Government (DCLG) (2012), "Fire and rescue service national framework for England: 2012", HMSO, London, available at: www.gov.uk/government/uploads/system/uploads/attachment_data/file/5904/nationalframew ork.pdf (accessed 28 April 2013).

7.

DiGuiseppi, C. and Higgins, J.P.T. (2000), "Systematic review of controlled trials of interventions to promote smoke alarms", Archives of Disease in Childhood, Vol. 82 No. 5, pp. 341-8. [CrossRef], [ISI] [Infotrieve]

8.

DiGuiseppi, C. , Roberts, I. , Wade, A. , Sculpher, M. , Edwards, P. , Godward, C. , Pan, H. and Slater, S. (2002), "Incidence of fires and related injuries after giving out free smoke 
alarms: cluster randomised controlled trial”, British Medical Journal, Vol. 325 No. 7371, pp. 995-7. [CrossRef], [ISI] [Infotrieve]

9.

Ewen, S. (2004), "Our fire and rescue service: a local, regional or national responsibility", History and policy, available at: www.historyandpolicy.org/papers/policy-paper-20.html (accessed 28 April 2013), p. -.

10.

Fire and Rescue Services Act (2004), HMSO, London, available at:

www.legislation.gov.uk/ukpga/2004/21/contents (accessed 25 February 2012).

11.

Fire Brigade's Union (FBU) (2012), "Floods threaten to expose the impact of frontline cuts and refusal to act on Key Pitt review proposal in England and Wales", available at: www.fbu.org.uk/?p=5686 (accessed 6 July 2012).

12.

Granito, J. (2009), "The value of research to fire rescue officers", International Fire Service Journal of Leadership and Management, Vol. 3 No. 1, pp. 5-8. [Infotrieve]

13.

Kendrick, D. , Groom, L. , Stewart, J. , Watson, M. , Mulvaney, C. and Casterton, R. (2007), "'Risk watch': cluster randomised controlled trial evaluating an injury prevention program", Injury Prevention, Vol. 13 No. 2, pp. 93-9. [CrossRef], [ISI] [Infotrieve]

14.

Localism Act (2011), HMSO, London, available at:

www.legislation.gov.uk/ukpga/2011/20/contents/enacted (accessed 6 July 2012).

15.

Lowton, K. , Laybourne, A.H. , Whiting, D.G. and Martin, F.C. (2010), "Can Fire and Rescue Services and the National Health Service work together to improve the safety and wellbeing of vulnerable older people? Design of a proof of concept study", BMC Health Services Research, Vol. 10, p. -. [ISI]

16.

McCaffrey, S.M. (2004), "Fighting fire with education: what is the best way to reach out to homeowners?", Journal of Forestry, Vol. 102 No. 5, pp. 12-9. [ISI] [Infotrieve]

17.

McGee, T.K. (2011), "Public engagement in neighbourhood level wildfire mitigation and preparedness: case studies from Canada, the US and Australia", Journal of Environmental Management, Vol. 92 No. 10, pp. 2524-32. [CrossRef], [ISI] [Infotrieve]

18.

Mallonee, S. (2000), "Evaluating injury prevention programs: the Oklahoma city smoke alarm project", Future of Children, Vol. 10 No. 1, pp. 164-74. [CrossRef], [ISI] [Infotrieve] 19.

Matheson, K. , Manning, R. and Williams, S. (2011), "From brigade to service: an examination of the role of fire and rescue services in modern local government", Local Government Studies, Vol. 37 No. 4, pp. 451-65. [CrossRef], [ISI] [Infotrieve]

20. 
Moeller, B.J. (2007), “Answering 'big questions' in the fire service”, International Fire Service Journal of Leadership and Management, Vol. 1 No. 2, pp. 11-6. [Infotrieve]

21.

Morton, S. (2006), "Community safety in practice - the importance of evaluation", Safer Communities, Vol. 5 No. 1, 12-7. [Abstract] [nfotrieve]

22.

Murphy, P. , Greenhalgh, K. and Parkin, C. (2012), "Fire and rescue service reconfiguration: a case study in Nottinghamshire", International Journal of Emergency Services, Vol. 1 No. 1, pp. 86-94. [Abstract] [Infotrieve]

23.

O'Connor, A. (1995), "Evaluating comprehensive community initiatives: a view from history", in Connell, J.P., Kubisch, A.C., Schorr, L.B. and Weiss, C.H. (Eds), New Approaches to Evaluating Community Initiatives, Concepts, Methods and Contexts, The Aspen Institute, Washington, DC.

24.

ONS (2013), "Crime and justice", available at: www.ons.gov.uk. (accessed 28 April 2013). 25.

Roberts, H. , Curtis, K. , Liabo, K. , Rowland, D. , DiGuiseppi, C. and Roberts, I. (2004), "Putting public health evidence into practice: increasing the prevalence of working smoke alarms in disadvantaged inner city housing", Journal of Epidemiology \& Community Health, Vol. 58 No. 4, pp. 280-5. [CrossRef], [ISI] [Infotrieve]

26.

Ta, V.M. , Frattaroli, S. , Bergen, G. and Gielen, A.C. (2006), "Evaluated community fire safety interventions in the United States: a review of current literature", Journal of Community Health, Vol. 31 No. 3, pp. 176-97. [CrossRef], [ISI] [nfotrieve]

27.

Terry, P. , Klassen, J. , MacKay, M. , Moher, D. , Walker, A. and Jones, A.L. (2000), "Community-based injury prevention intervention", The Future of Children: Unintentional Injuries in Childhood, Vol. 10 No. 1, pp. 83-110. [Infotrieve]

28.

Wentling, R.M. (2000), "Evaluation of diversity initiatives in multi-national corporations", Human Resource Development International, Vol. 3 No. 4, pp. 435-50. [CrossRef] [nfotrieve]

Further reading

1.

Department for Communities and Local Government (2010a), "Evaluation options for fire and rescue service safety activities", Fire research report, London, May, available at: www.gov.uk/government/uploads/system/uploads/attachment_data/file/6332/1784013.pdf (accessed 28 April 2013).

2.

Department for Communities and Local Government (2010b), "Fire futures: localism and accountability report', HMSO, London, available at: 
www.gov.uk/government/uploads/system/uploads/attachment_data/file/136128/localism_and _accountability.pdf (accessed 28 April 2013).

3.

Department for Communities and Local Government (DCLG) (2011a), "The economic costs of fire: estimates for 2008', available at:

https://webarchive.nationalarchives.gov.uk/20121108165934/;

www.communities.gov.uk/documents/corporate/pdf/1838338.pdf (accessed 25 February 2012).

4.

Department for Communities and Local Government (DCLG) (2011b), "The economic costs of fire: estimates for 2008", available at:

www.communities.gov.uk/documents/corporate/pdf/1838338.pdf (accessed February 2011).

5.

Laybourne, A.H. , Martin, F.C. , Whiting, D.G. and Lowton, K. (2011), "Could fire and rescue services identify older people at risk of falls?", Primary Health Care Research \& Development, Vol. 12 No. 4, pp. 395-9. [CrossRef] [Infotrieve]

6.

The Chief Fire Officer's Association (2010), Project Planning and Evaluation Workbook: A Step by Step Guide to Evaluation - Section 4.4, CFAO, available at: www.cfoa.org.uk/ (accessed 10 October 2011).

\section{About the authors}

Section:_i26_i26

Thomas Simpson became a member of the Emergency Services Research Unit at the Nottingham Trent University in November 2010, commencing a two-year long Knowledge Transfer Partnership research project with Nottinghamshire Fire and Rescue Service. The project has focused upon developing evaluation methods which can be used to assess the impact fire and rescue service community safety work. Thomas is also working towards an MSc in applied research and evaluation methods at the Nottingham Trent University.

Dr Dan Wheatley is a Senior Lecturer in Economics at the Nottingham Trent University. He is a member the Nottingham Business School and of the Applied Economics and Policy research group. Areas of interest include work-time, work-life balance, flexible working, travel-to-work, and dual career households. He has published in Personnel Review, Review of Social Economy, Review of Political Economy and American Journal of Economics and Sociology.

Vivienne Brunsden is a Principal Lecturer in Psychology and the Director of the Emergency Services Research Unit (ESRU) at the Nottingham Trent University. Her personal research interests are focussed on psychological issues relating fire and rescue service working and on humanitarian issues in disaster. She is the Editor in Chief of the International Journal of Emergency Services and convenes an international conference on emergency management. Vivienne Brunsden is the corresponding author and can be contacted at: vivienne.brunsden@ntu.ac.uk

Rowena Hill is a Senior Lecturer of Psychology and a Member of the Emergency Services Research Unit at the Nottingham Trent University. Her research interests reflect the breadth of psychological and interdisciplinary topics addressed by ESRU from operational aspects to leadership. 
